\title{
The role of cell therapy in neurosurgery
}

\section{November 2002}

\section{John F. Alksne, M.D.}

\section{Division of Neurosurgery, UCSD Medical Center, San Diego, California}

Gene, stem cell, and cell therapies in general have not yet achieved the role postulated by some and hoped for by many in the treatment of neurological disorders. Nevertheless, great potential remains, and significant advancements continue to be made in the laboratory and clinical setting. As such, the neurosurgical community needs to be aware of the progress and the pitfalls to be prepared for the future. This issue of Neuro-

Neurosurg. Focus / Volume 13 / November, 2002 surgical Focus attempts to fulfill this need by highlighting the current status of cell therapy in the treatment of patients with Parkinson disease, on which the greatest amount of clinical data have been reported. In addition, a brief glimpse into the future is provided by articles on the possible roles of cell therapy in patients with stroke and Alzheimer disease, which are two of the most prevalent neurological disorders. 